\author{
Klaus-Dieter Drüen
}

\title{
Die Indienstnahme Privater für den Vollzug von Steuergesetzen
}

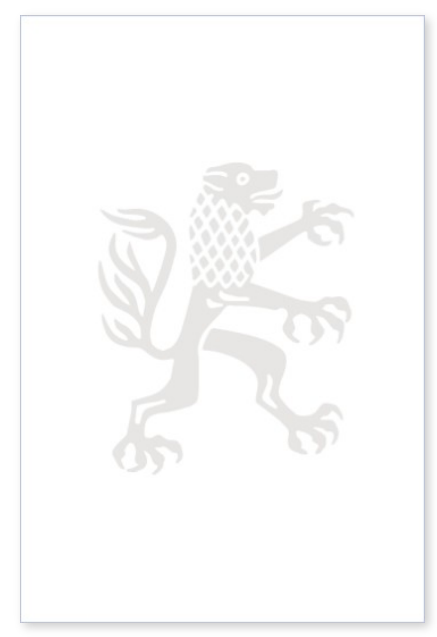

2012. XX, 450 Seiten. JusPubl 218

ISBN 978-3-16-152420-2

DOI 10.1628/978-3-16-152420-2

eBook PDF $129,00 €$

ISBN 978-3-16-150340-5

Leinen $129,00 €$
Die gesetzliche Indienstnahme Privater hat Tradition. Im Jahre 1950 hat Hans Peter Ipsen diese Rechtsfigur entdeckt und das Bundesverfassungsgericht hat sie bald rezipiert. Sie ist auch in der Staatsrechtslehre auf fruchtbaren Boden gefallen, aber kaum vertieft beleuchtet worden. Bislang zu wenig hinterfragte Rechtfertigungsschleifen begreift der Gesetzgeber augenscheinlich als Einladung, Bürgern und Wirtschaft neue Pflichten im öffentlichen Interesse oder zur Entlastung des Staates aufzuerlegen, obwohl die Politik sich den Bürokratieabbau auf die Fahnen geschrieben hat. Ausgehend vom Referenzgebiet der Indienstnahme Privater für den Steuervollzug, das Ipsen historisch mit dem Lohnsteuerabzug durch den Arbeitgeber vor Augen stand, zeigt Klaus-Dieter Drüen verfassungsrechtliche Strukturen und Typen dieser Rechtsfigur auf. Der Autor liefert einen Baustein zum vielschichtigen Indienstnahmerecht, um das derzeit wissenschaftlich intensiv gerungen wird.

Klaus-Dieter Drüen Geboren 1969; Ausbildung zum Diplom Finanzwirt in der Finanzverwaltung NRW; Studium der Rechtswissenschaft in Bochum; 1998 Promotion; 2005 Habilitation; derzeit Inhaber des Lehrstuhls für Unternehmenssteuerrecht an der Heinrich-Heine-Universität Düsseldorf.

Jetzt bestellen:

https://mohrsiebeck.com/buch/die-indienstnahme-privater-fuer-den-vollzug-von-steuergesetzen-9783161524202?

no_cache=1

order@mohrsiebeck.com

Telefon: +49 (0)7071-923-17

Telefax: +49 (0)7071-51104 